\title{
Driving pressure and long-term outcomes in moderate/severe acute respiratory distress syndrome
}

\author{
Carlos Toufen Junior ${ }^{*}$ (D), Roberta R. De Santis Santiago ${ }^{1}$, Adriana S. Hirota', Alysson Roncally S. Carvalho ${ }^{2,3}$, \\ Susimeire Gomes ${ }^{1}$, Marcelo Brito Passos Amato ${ }^{4}$ and Carlos Roberto Ribeiro Carvalho ${ }^{1}$
}

\begin{abstract}
Background: Acute respiratory distress syndrome (ARDS) patients may present impaired in lung function and structure after hospital discharge that may be related to mechanical ventilation strategy. The aim of this study was to evaluate the association between functional and structural lung impairment, N-terminal-peptide type III procollagen (NT-PCP-III) and driving pressure during protective mechanical ventilation. It was a secondary analysis of data from randomized controlled trial that included patients with moderate/severe ARDS with at least one follow-up visit performed. We obtained serial measurements of plasma NT-PCP-III levels. Whole-lung computed tomography analysis and pulmonary function test were performed at 1 and 6 months of follow-up. A health-related quality of life survey after 6 months was also performed.
\end{abstract}

Results: Thirty-three patients were enrolled, and 21 patients survived after 6 months. In extubation day an association between driving pressure and NT-PCP-III was observed. At 1 and 6 months forced vital capacity (FVC) was negatively correlated to driving pressure $(p<0.01)$. At 6 months driving pressure was associated with lower FVC independently on tidal volume, plateau pressure and baseline static respiratory compliance after adjustments $\left(r^{2}=0.51\right.$, $p=0.02$ ). There was a significant correlation between driving pressure and lung densities and nonaerated/poorly aerated lung volume after 6 months. Driving pressure was also related to general health domain of SF-36 at 6 months.

Conclusion: Even in patients ventilated with protective tidal volume, higher driving pressure is associated with worse long-term pulmonary function and structure.

\section{Background}

Acute respiratory distress syndrome (ARDS) is a rapidly progressive illness associated with high mortality and morbidity [1-3]. Up to 5 years after discharge from the intensive care unit (ICU), ARDS survivors still present persistent disabilities, including muscle weakness, altered lung function (e.g., decreased lung volumes, or decreased lung diffusion capacity) and an impaired mental health and cognition [4].

\footnotetext{
*Correspondence: toufenjr@usp.br

${ }^{1}$ Divisão de Pneumologia, Cardiopulmonary Department, Heart Institute (InCor) University of São Paulo, INCOR Av. Dr. Enéas de Carvalho Aguiar, 44 Pinheiros, São Paulo, SP CEP 05403-900, Brazil

Full list of author information is available at the end of the article
}

About 25\% of ARDS survivors present some reduction in the forced vital capacity (FVC) and in diffusion capacity 6 months after discharge [5]. Among ARDS survivors, abnormal findings in chest tomography correlate with restrictive lung changes and poorer health-related quality of life (HRQoL), suggesting that pulmonary dysfunction could be associated with limited activity in these patients [6].

The risk factors for a reduced long-term lung function in ARDS patients are unknown. As protective mechanical ventilation is an important intervention to reduce mortality of ARDS, probably by decreasing lung inflammation, we hypothesized that the parameters used during the ventilation strategy could be related to long-term lung fibrosis, impairing the lung function among ARDS survivors. 
During a recent ARDS trial [7] comparing two strategies of protective mechanical ventilation, we collected lung function data for survivors, during the first 6 months after ARDS onset. We decided to explore the relationship between ventilator settings and long-term outcomes for the entire cohort. Supporting this analysis, we also assessed the acute production of N-terminalpeptide type III procollagen (NT-PCP-III), from enrollment till weaning, as well as other long-term outcomes such as quantitative computed tomography (which enabled us to estimate excess tissue reorganization), 6-min walk test (6MWT) and quality of life (QoL).

\section{Methods}

\section{Study design}

We conducted a prospective longitudinal cohort study of 22 survivors of moderate/severe ARDS, recruited from six different ICUs located in Hospital das Clínicas, São Paulo, Brazil, from November 2008 to January 2012.

\section{Patient selection}

Patients were enrolled in this study in conjunction with a clinical trial in mechanical ventilation, the "ARDSnet Protocol versus Open Lung Approach in ARDS" trial (NCT 00431158) [7]. The institutional review committee approved the study that included the follow-up, and informed consent was obtained from each patient or legal representative. Briefly, this was a randomized controlled trial in which patients were ventilated with a ARDSnet protocol, which uses low tidal volumes, relatively high respiratory rates, with oxygenation managed according to PEEP and FIO2 relationships as defined in a table, or with an open lung approach strategy, which uses a technique to recruit collapsed lung areas and then uses the lowest PEEP level that prevents recollapse of recruited lung units, being the best PEEP level determined by a decremental PEEP trial involving a series of pressure measurements taken after the recruitment maneuver. Both the ARDSnet protocol and the open lung approach require low tidal volumes and plateau pressures. In conclusion, open lung approach improved oxygenation and driving pressure, without detrimental effects on mortality, ventilator-free days or barotrauma.

The inclusion criteria for the study were as follows: Patients intubated and mechanically ventilated, with diagnosis of ARDS using American-European Consensus Criteria and enrollment in study $<48 \mathrm{~h}$ since diagnosis of ARDS. For 12-36 h (ideally 12-24 h), after diagnosis of ARDS, patient must be ventilated as follows: volume $A / C$, tidal volume of $4-8 \mathrm{~mL} / \mathrm{kg} \mathrm{PBW}$, plateau pressure $\leq 30 \quad \mathrm{cmH}_{2} \mathrm{O}, \quad \mathrm{PEEP} / \mathrm{FIO}_{2}$ adjustments using ARDSnet table, and ventilator rate to keep $\mathrm{PaCO}_{2}=35-60 \mathrm{mmHg}$. During the $12-36$-h (ideally 12-24-h) period, $\mathrm{PaO}_{2} / \mathrm{FIO}_{2}$ must remain $<200 \mathrm{~mm} \mathrm{Hg}$ for an ABG obtained $30 \mathrm{~min}$ after placement on the following specific ventilator settings: volume $A / C$, tidal volume $=6 \mathrm{~mL} / \mathrm{kg} \mathrm{PBW}$, plateau pressure $\leq 30 \mathrm{cmH}_{2} \mathrm{O}$, inspiratory time $\leq 1 \mathrm{~s}, \mathrm{PEEP} \geq 10 \quad \mathrm{cmH}_{2} \mathrm{O}, \mathrm{FIO}_{2} \geq 0.5$, ventilator rate to keep $\mathrm{PaCO}_{2}=35-60 \mathrm{mmHg}$. No lung recruitment maneuvers or adjunct therapy. Total time on mechanical ventilation $<96 \mathrm{~h}$ at time of randomization.

Patients were excluded if they presented one of the following criteria: age $<18$ years or $>80$ years, weight $<35 \mathrm{~kg}$ PBW, body mass index $>60$, intubated $2^{\circ}$ to acute exacerbation of a chronic pulmonary disease, acute brain injury (ICP $>18 \mathrm{mmHg}$ ), immunosuppression $2^{\circ}$ to chemo- or radiation therapy, severe cardiac disease (one of the following): New York Heart Association Class 3 or 4, acute coronary syndrome or persistent ventricular tachyarrhythmias, positive laboratory pregnancy test, sickle cell disease, neuromuscular disease, high risk of mortality within 3 months from cause other than ARDS, e.g., cancer, more than 2 organ failures (not including pulmonary system), documented lung barotrauma, i.e., chest tube placement other than for fluid drainage, persistent hemodynamic instability or intractable shock, penetrating chest trauma, enrollment in another interventional study. Randomization in the pivotal study was stratified by center, age and APACHE II scores.

\section{Measurements}

Baseline data collected at enrollment included age, sex, height, severity of illness measured by the Acute Physiology and Chronic Health Evaluation (APACHE) II score, ratio between arterial oxygen tension and fraction of inspired oxygen $\left(\mathrm{PaO}_{2} / \mathrm{F}_{\mathrm{I}} \mathrm{O}_{2}\right)$ with a positive end-expiratory pressure (PEEP) of at least $10 \mathrm{cmH}_{2} \mathrm{O}$ and $\mathrm{FIO}_{2} \geq 0.5$, and static compliance (respiratory system) $30 \mathrm{~min}$ before protocol enrollment. Twenty-four hours after patient enrollment, we collected respiratory variables, including tidal volume ( $\mathrm{mL} / \mathrm{kg}$ of predicted body weight), PEEP and plateau pressure. Airway driving pressure was defined as plateau pressure minus total PEEP. To measure the plateau pressure we used neuromuscular blocking agents and volume-controlled ventilation.

Blood samples were obtained on the day of randomization (day 0) and on days 1, 3, 7, and the day of extubation. Blood samples were centrifuged, and plasma was stored at 70 C. NT-PCP-III was assayed by a sandwich ELISA method according to the methodology specifications of the manufacturer (Elabscience, Texas, USA). The normal range of serum levels of nonsmoking individuals was determined to be $1.6-4.0 \mathrm{ng} / \mathrm{L}$.

Pulmonary function testing (PFT) was performed at 1 and 6 months after the onset of ARDS using the MedGraphics Cardiorespiratory Diagnostic System (Medical 
Graphics Corporation, USA). All tests were done according to Brazilian guidelines [8]. Reference ranges were calculated based on statistics formulated from the Brazilian population [9-11].

High-resolution computed tomography (HRCT) scan of the lungs was also performed 1 and 6 months after the onset of ARDS in supine position during inspiration, close to total lung capacity. All CT scans were segmented by applying the region growing algorithm to select the lung parenchyma using OsiriX (OsiriX 64-bits, Pixmeo Sarl, Geneva, Switzerland). After the segmentation, the original images (DICOM files) as well as each respective ROI were exported and analyzed with a purpose-built routine (QALI-DV software) written in MATLAB (MathWorks, USA). Manual correction was applied to the segmented images containing peripheral atelectasis. Total lung volume (TLV), total air volume (TAV) and total lung mass (TLM) were extracted from the segmented whole lung in 3D [11, 12]. The percentages of hyperaerated $(-1000$ to $-900 \mathrm{HU})$, normally aerated $(-900$ to -500 $\mathrm{HU})$, poorly aerated $(-500$ to $-100 \mathrm{HU}$ ) and nonaerated $(-100$ to $+100 \mathrm{HU})$ compartments of the lung parenchyma were calculated $[12,13]$. To assess the occurrence and progression of emphysema in this longitudinal study we used the percentile point [14-17] using a threshold of 15\% (P15). The sensitivity of the percentile point method has been shown to be similar within a broad range of percentiles from the 10th to the 30th [14].

Six months after ARDS onset, we also performed a standardized 6MWT [18] and fulfilled the Medical Outcomes Study 36-item Short-Form General Health Survey (SF-36), which measures the HRQoL [19]. The SF-36 includes eight multiple-item scales that assess physical functioning, social functioning, physical role, emotional role, mental health, pain, vitality and general health. Scores for each aspect can range from 0 (worst) to 100 (best).

\section{Statistical analysis}

Categorical values are described as frequency and percentages, and continuous variables as the mean and SD, or median and interquartile range. The Fisher exact test was used to compare independent categorical variables. Continuous variables were compared with the Student $t$ test or the Mann-Whitney test for dependent or independent data. The Friedman test was used for one-way repeated-measures analysis. The strength of the association between two variables was measured using correlation coefficient $(r)$. We used Pearson correlation to parametric variable and Spearman correlation to nonparametric variable. We used linear regression to get $r^{2}$ in parametric variable. In order to determine clinical variables independently associated with lung function, we performed a multivariable linear regression. For NTPCP-III regression we used $\log 10$ transformations as is commonly performed for biomarkers with a right-tailed distribution. Statistical significance was set at a twotailed $p$ value of $\leq 0.05$, and analyses were performed with $R$, version 3.0.2 (http://www.r-project.org).

\section{Results}

\section{Characteristics of the population}

Over the 58-month (2007-2012) recruitment period, we enrolled 33 patients. The patients in cohort were predominantly male. Mortality at 28 th day was $33 \%$ (Fig. 1).

Of those enrolled, we lost the follow-up of 5 patients at month- 1 and 2 between month- 1 and month- 6 . Reasons for exclusion are outlined in Fig. 1. There was no difference in terms of severity score, age and static compliance measurement between patients followed up at month- 6 and patients that were lost.

The descriptive baseline and hospital data for all randomized patients and for survivors are described in Table 1. Monitored variables during mechanical ventilation at baseline and $24 \mathrm{~h}$ after randomization are also shown in Table 1. Driving pressure at $24 \mathrm{~h}$ was related to driving pressure at $48 \mathrm{~h}(r=0.58, P=0.006)$ and $72 \mathrm{~h}$ $(r=0.56, P=0.009)$ after randomization.

\section{Pulmonary function tests analysis}

Pulmonary function tests showed a mildly reduced FVC and a moderately reduced $\mathrm{DL}_{\mathrm{CO}}$ after 6 months (Table 2). The FVC was below normal $(<80 \%$ of predicted) in eleven (65\%) patients at month-1, and in five (33\%) patients at month-6. Twelve patients (70\%) showed a reduced $\mathrm{DL}_{\mathrm{CO}}$ at month-1, whereas four (29\%) patients showed a reduced $\mathrm{DL}_{\mathrm{CO}}$ after 6 months of follow-up (Table 2).

Driving pressure was the only ventilation variable significantly correlated with FVC at $1-(r=0.65)$ and 6-month $(r=0.67)$ follow-up (Fig. 2). Driving pressure $(r=0.51)$ and APACHE II $(r=0.59)$ were correlated with $\mathrm{DL}_{\mathrm{CO}}$ at month-1. Of note, tidal volume and respiratory system compliance were very weakly correlated with pulmonary function tests.

After testing for the confounding effects of tidal volumes, plateau pressures and baseline static respiratory compliance $\left(R^{2}=0.51, F(4,10)=4.66, p=0.022\right)$, the association between driving pressures and FVC at month- 6 remained the only statistically significant one $(\beta=-4.62$, IC95\% ( -7.11 to -2.13$), P=0.002)$.

When comparing the effects of the randomized treatments (OLA vs. ARDSnet) on FVC at month-6, there was a marginal difference between arms, with FVC of $4.54 \pm 0.93 \mathrm{~L}$ versus $3.41 \pm 1.04 \mathrm{~L}$ (OLA vs. ARDSnet, respectively, $P=0.06$ ), representing $96 \pm 20 \%$ versus $86 \pm 15 \%$ of predicted, respectively $(P=0.32)$. 


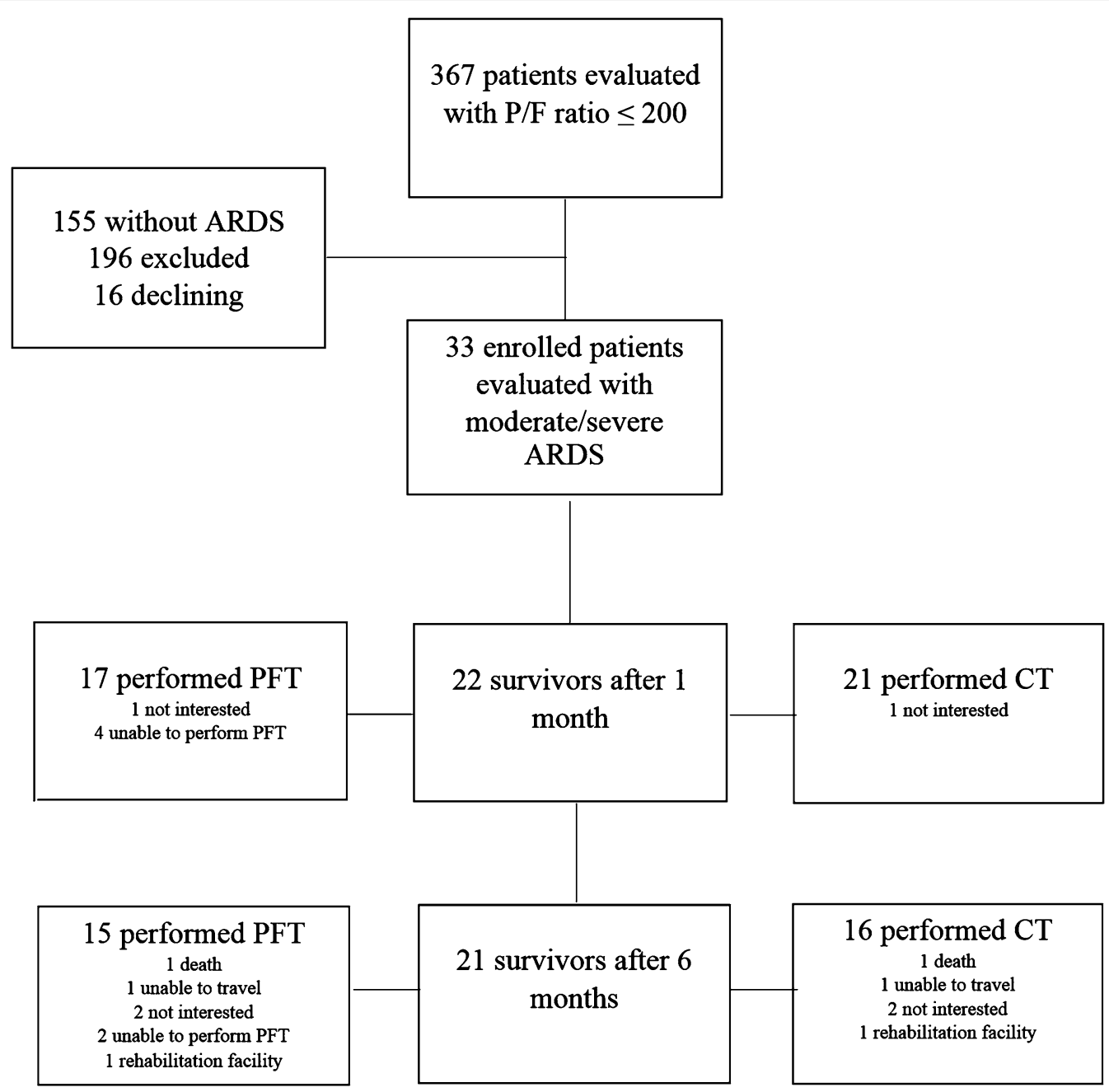

Fig. 1 Chart of the protocol

\section{CT scan analysis}

Twenty-one patients were performed a HRCT at month-1 of follow-up. The median and interquartile range of the total lung volume (TLV) was 3.54 L (2.294.37); the total lung weight (TLW) was $1194 \mathrm{~g}$ (8611873 ), and the mean pulmonary density (MPD) was $451 \mathrm{~g} / \mathrm{L}(243-610)$. The $\mathrm{P}_{15}$ (percentile $15 \%$ for lowest lung densities) was $72 \mathrm{~g} / \mathrm{L}(42-117)$.

At month-6, 16 patients were performed a HRCT. The median and interquartile range of TLV increased $(P=0.01)$ to $4.99 \mathrm{~L}(3.73-6.20)$, the TLW decreased $(P=0.01)$ to $762 \mathrm{~g}(652-934 \mathrm{~g})$, the MPD decreased $(P<0.001)$ to $164 \mathrm{~g} / \mathrm{L}(133-183)$, and $\mathrm{P}_{15}$ decreased $(P=0.02)$ to $49 \mathrm{~g} / \mathrm{L}(23-65)$. Those longitudinal reductions in MPD, TLM and percent of nonaerated/poorly aerated lung volumes were all significant, as well as the increase in TLV.

Lung image parameters were significantly correlated with driving pressure and pulmonary function. After 6 months, individual MPD was significantly correlated with individual driving pressure $(r=0.53, P=0.03)$, but not with respiratory system compliance $(P=0.95)$. Consistently, FVC at month-6 strongly correlated with CT parameters: MPD $(r=-0.86, P=0.00005), \%$ of nonaerated/poorly aerated volume $(r=-0.70, P=0.003)$, TLV $(r=0.65, P=0.008)$ and air/tissue volume ratio $(r=0.70$, $P=0.003)$.

Dividing patients based on median into high (HDP) or low (LDP) driving pressure groups $(\geq 13$ and $<13 \mathrm{cmH}_{2} \mathrm{O}$, respectively), MDP was higher in HDP group ( $P=0.04$; Fig. 3$)$. 
Table 1 Demographic characteristics and mechanical ventilation variables from randomized and surviving ARDS patients

\begin{tabular}{|c|c|c|c|c|}
\hline Characteristics & $\begin{array}{l}\text { Randomized patients } \\
(N=33)\end{array}$ & Surviving patients $(N=22)$ & $\begin{array}{l}\text { Nonsurviving patients } \\
(n=11)\end{array}$ & $P$ value \\
\hline Age, year & $49 \pm 14.9$ & $48.5 \pm 13.9$ & $50 \pm 16.7$ & 0.80 \\
\hline Sex, \% male & $22(66.7)$ & $15(68)$ & $7(46.7)$ & 1.00 \\
\hline Smokers (\%) & $10(30)$ & $7(28)$ & $3(27)$ & 1.00 \\
\hline \multicolumn{5}{|l|}{ Origin of ARDS } \\
\hline Primary N, \% & $23(70)$ & $17(77)$ & $6(55)$ & \multirow[t]{2}{*}{0.24} \\
\hline Secondary N, \% & $10(30)$ & $5(23)$ & $5(45)$ & \\
\hline \multicolumn{5}{|l|}{ Baseline data } \\
\hline APACHE II & $19.6 \pm 10.5$ & $17.1 \pm 5.3$ & $24.5 \pm 16.0$ & 0.16 \\
\hline P/F ratio & $129 \pm 32$ & $135 \pm 34$ & $118 \pm 23$ & 0.09 \\
\hline Tidal volume, mL/kg PBW & $5.9(5.7-6.0)$ & $5.9(5.5-6.0)$ & $5.9(5.9-6.4)$ & 0.78 \\
\hline Driving pressure, $\mathrm{cmH}_{2} \mathrm{O}$ & $13.5 \pm 4$ & $13.2 \pm 3.9$ & $14.1 \pm 4.3$ & 0.58 \\
\hline Plateau pressure, $\mathrm{cmH}_{2} \mathrm{O}$ & $25.4 \pm 3.8$ & $25.3 \pm 4.2$ & $25.6 \pm 3.3$ & 1.00 \\
\hline PEEP, $\mathrm{cmH}_{2} \mathrm{O}$ & $10(10-14)$ & $10(10-14)$ & $10(10-13)$ & 0.69 \\
\hline $\mathrm{C}_{\text {stat, }} \mathrm{mL} / \mathrm{cmH}_{2} \mathrm{O} / \mathrm{kg} \mathrm{PBW}$ & $0.48 \pm 0.15$ & $0.47 \pm 0.15$ & $0.50 \pm 0.16$ & 0.69 \\
\hline \multicolumn{5}{|l|}{ Data $24 \mathrm{~h}$ after inclusion } \\
\hline OLA arm patients, $\%$ & $18(54 \%)$ & $11(50 \%)$ & $7(63 \%)$ & 0.71 \\
\hline P/F ratio & $173 \pm 62$ & $174 \pm 57$ & $170 \pm 70$ & 0.96 \\
\hline Tidal volume, mL/PBW & $5.3 \pm 1.1$ & $5.5 \pm 0.9$ & $4.9 \pm 1.4$ & 0.20 \\
\hline Driving pressure, $\mathrm{cmH}_{2} \mathrm{O}$ & $11(10-14)$ & $11(10-14)$ & $12(10-12.5)$ & 0.92 \\
\hline Plateau pressure, $\mathrm{cmH}_{2} \mathrm{O}$ & $28(26-30)$ & $27.5(26.2-30)$ & $30(24.5-31)$ & 0.48 \\
\hline PEEP, $\mathrm{cmH}_{2} \mathrm{O}$ & $15.4 \pm 5.1$ & $15.3 \pm 4.9$ & $15.5 \pm 5.5$ & 0.93 \\
\hline $\mathrm{C}_{\text {stat, }} \mathrm{mL} / \mathrm{cmH}_{2} \mathrm{O} / \mathrm{kg} \mathrm{PBW}$ & $0.44(0.40-0.53)$ & $0.45(0.41-0.54)$ & $0.43(0.37-0.47)$ & 0.19 \\
\hline Days of ventilator use & $9(6.5-13.5)$ & $9(6.2-11.7)$ & $12(10-14.5)$ & 0.14 \\
\hline ICU length of stay, days & $16(11.7-24)$ & $18.5(12-24.7)$ & $15(12.5-17)$ & 0.26 \\
\hline Hosp. length of stay, days & $27.5(16.7-56.7)$ & $34(20.7-73.5)$ & $21(15-25)$ & 0.02 \\
\hline
\end{tabular}

Parametric data are presented as mean \pm 1 standard deviation or median (first and third quartiles)

$\mathrm{P} / \mathrm{F}$ ratio $\mathrm{PaO}_{2} / \mathrm{FIO}_{2}$ ratio, $\mathrm{PBW}$ predicted body weight and $C_{\text {stat }}$ static compliance

Table 2 Lung function during the follow-up

\begin{tabular}{lcc}
\hline & 1 Month (N=17) & 6 Months $(\mathbf{N}=\mathbf{1 5})$ \\
\hline FVC (L) & $3.34 \pm 0.77$ & $3.78 \pm 1.11$ \\
FVC (\% predicted) & $80 \pm 16$ & $89 \pm 17$ \\
FEV1/FVC ratio & $0.81 \pm 0.05$ & $0.78 \pm 0.06$ \\
FEV1/FVC ratio (\% predicted) & $99 \pm 5$ & $97 \pm 8$ \\
TLC (L) & $4.96 \pm 1.18$ & $5.57 \pm 1.36$ \\
TLC (\% of predicted) & $82 \pm 17$ & $89 \pm 18$ \\
RV (L) & $1.71 \pm 0.55$ & $1.75 \pm 0.49$ \\
RV (\% predicted) & $98 \pm 27$ & $97 \pm 21$ \\
DLCO & $17.8 \pm 6.1$ & $24.0 \pm 8.1$ \\
DLCO (\% predicted) & $55 \pm 17$ & $71 \pm 17$
\end{tabular}

All data are presented as mean \pm 1 standard deviation

FVC forced vital capacity, FEV1 forced expiratory volume in $1 \mathrm{~s}, T L C$ total lung capacity, $R V$ residual volume and $D L c o$ diffusing capacity of the lung for carbon monoxide
When comparing the effects of the randomized treatments (OLA vs. ARDSnet) on MPD at month-6, there was no difference, with MPD of 175 (131-176) g/L versus 171 (138-195) g/L (OLA vs. ARDSnet, respectively, $P=0.92)$. There was no difference in terms of TLV $(P=0.38)$ and TLW $(P=0.35)$.

\section{NT-PCP-III}

From the 28 patients, 106 blood specimens were available for analysis of NT-PCP-III levels. All plasma samples had elevated levels, considering normal values, and considering the samples collected after $24 \mathrm{~h}$ from inclusion, after 3 days, and after 7 days or weaning time, the level increased over time $(P=0.03)$.

Individual increments in $\log _{10}$ NT-PCP-III levels, from baseline till extubation, correlated with individual values of driving pressures at $24 \mathrm{~h}(\beta=0.006$, IC95\% (0.001$0.011), r^{2}=0.35, F(1,13)=8.55, p=0.011$; Fig. 4$)$ : the higher the driving pressure, the higher the increment in $\log _{10}$ NT-PCP-III difference. 

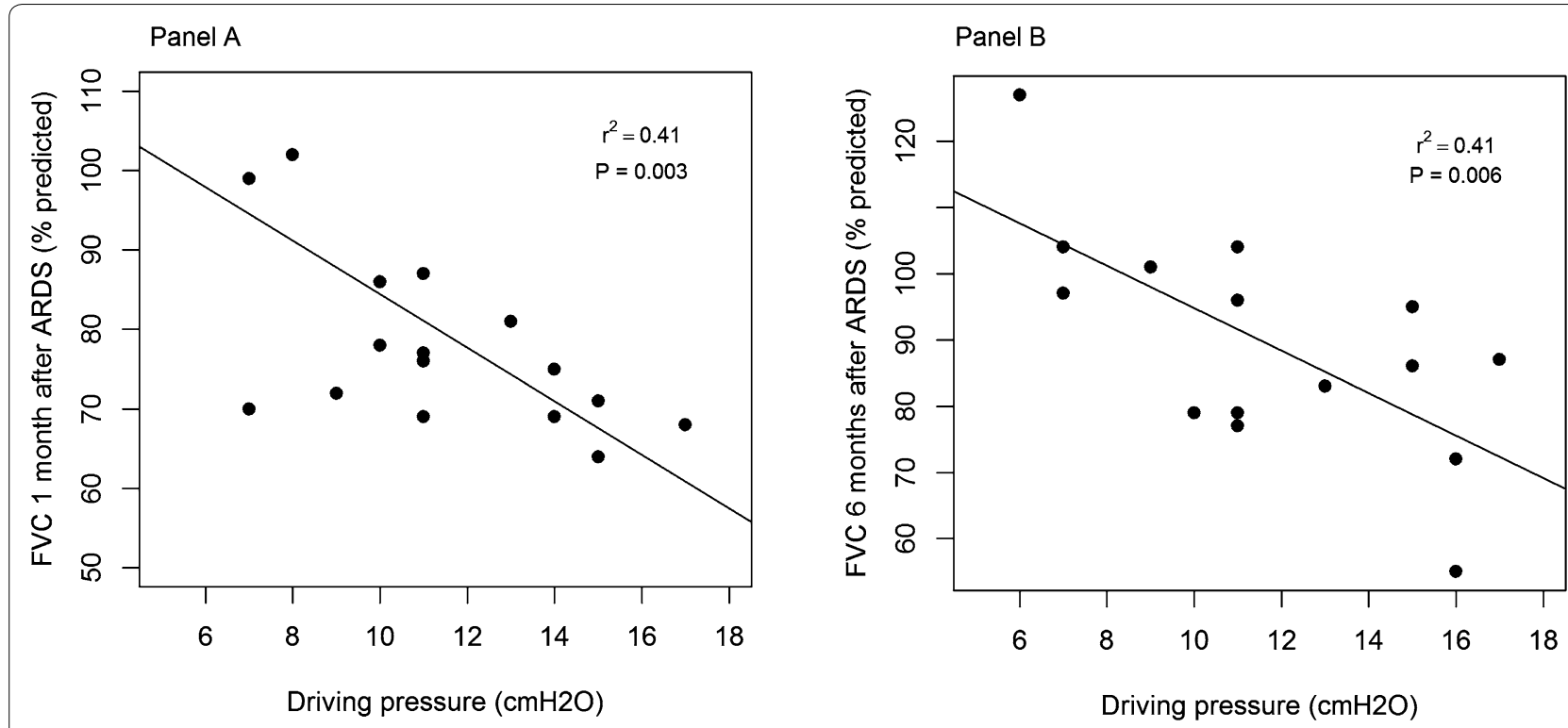

Fig. 2 Relationship between driving pressure and forced vital capacity after 1 month (panel A) and 6 months (panel B) of acute respiratory distress syndrome

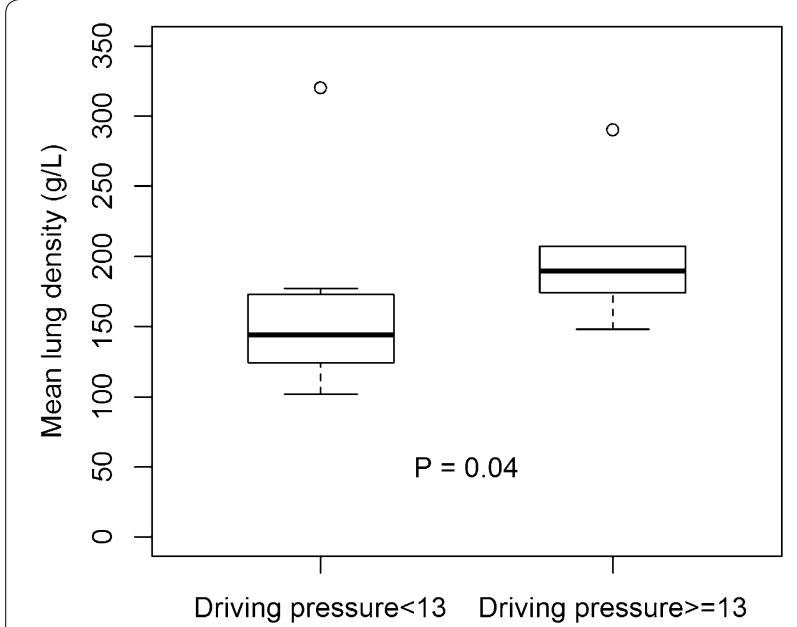

Fig. 3 Mean pulmonary parenchyma density in the whole-lung $C T$ scan in 17 ARDS patients after 6 months of follow-up split based on driving pressure median

Mean pulmonary density (MPD) at month-6 was related to $\log _{10}$ NT-PCP-III level during the first week of mechanical ventilation: at day $0 \quad(\beta=0.005$, IC95\% $\left.(0.001-0.010), r^{2}=0.35, F(1,12)=8.06, p=0.014\right)$, day 1 ( $\beta=0.006$, IC95\% $(0.002-0.010), r^{2}=0.34, F(1,14)=8.84$, $p=0.010)$, day $3(\beta=0.005$, IC95\% $(0.0003-0.009)$, $\left.r^{2}=0.25, F(1,12)=5.38, p=0.038\right)$.

Dividing patients into high (HDP) or low (LDP) driving pressure groups ( $\geq 13$ and $<13 \mathrm{cmH}_{2} \mathrm{O}$, respectively), LDP group did not change levels over time $(P=0.15)$, while HDP group increased ( $P=0.03$; Fig. 5$)$.
When comparing the effects of the randomized treatments (OLA vs. ARDSnet) on $\log _{10}$ NT-PCP-III, there was no statistic significant difference at day $0(P=0.89)$, day 1 $(P=0.55)$, day $3(P=0.19)$ and on extubation $(P=0.65)$. There was a difference in terms of $\log _{10}$ NT-PCP-III at day 7 (median $\log _{10}$ NT-PCP-III 1.69 in OLA arm vs. 1.99 in ARDSnet, $P=0.03)$. There was no difference in the change between day 0 to day $1(p=0.69)$, to day 3 $(p=0.23)$, to day $7(p=0.31)$ and to extubation $(p=0.18)$.

\section{Other tests' analysis}

A standardized 6MWT was performed in 11 patients, but we could not observe any relationship between the walked distance and the ventilation variables selected. In terms of HRQoL, 10 patients completed SF-36 survey and we found a correlation between driving pressure (24 $\mathrm{h}$ after randomization) and the general health domain $(r=-0.69, p=0.02)$.

\section{Discussion}

In a population of patients surviving an episode of moderate to severe ARDS, there was a negative correlation between airway driving pressures, measured during the first $24 \mathrm{~h}$ of mechanical ventilation, and forced vital capacity (FVC) measured after 6 months of ARDS onset. This early measurement of driving pressure was representative of the applied strategy of protective ventilation, adjusted right after randomization and persisting at similar levels during the following days [20], and did not correlate with baseline compliance of the respiratory system. 


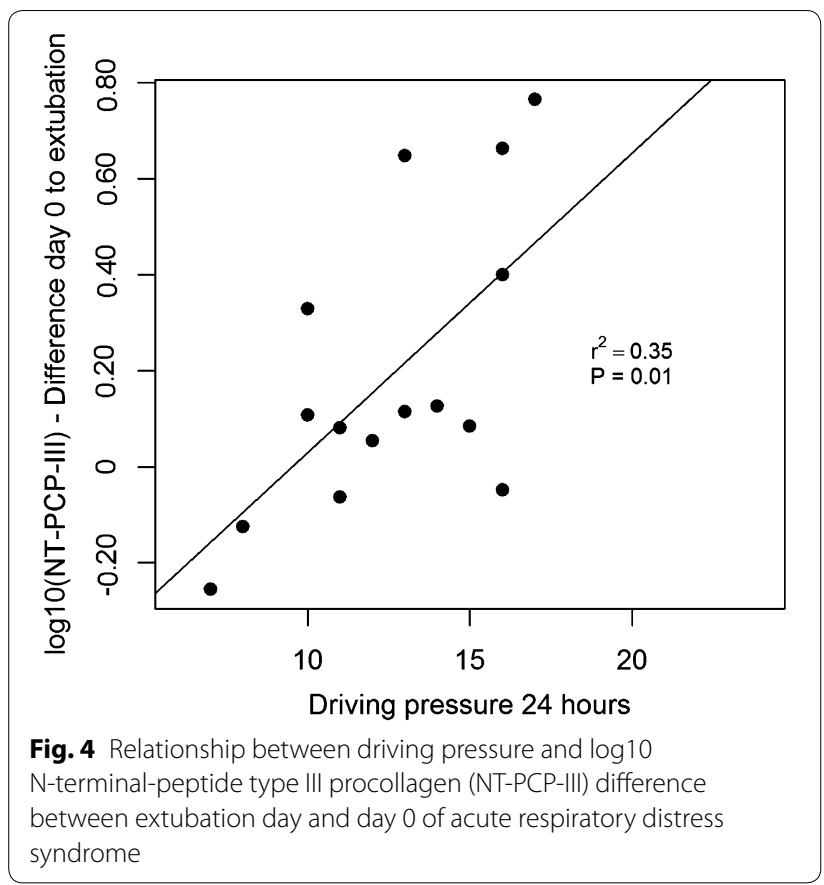

Also, we did not observe any relationship between tidal volumes (expressed in $\mathrm{mL} / \mathrm{PBW}$ ) and long-term pulmonary function tests.

Several studies involving ARDS survivors have shown a significant reduction in long-term lung function in a substantial proportion of patients, with a quarter of the patients presenting a FVC lower than $70 \%$ of predicted
$[5,21]$. In this subgroup of patients, the reduction in FVC was correlated with higher CT scores, but not with higher weakness score (acquired ICU weakness score), suggesting that the reduction in pulmonary function was related to lung fibrosis [6]. In fact, we observed an association between driving pressure and NT-PCP-III, a marker of fibrogenesis, paralleled by increased mean densities of the parenchyma, especially in those patients ventilated with higher driving pressure (Fig. 3). In those long-term studies, the changes in HRCT and in pulmonary function tests were both related to a poorer QoL [22]. In our study, the QoL could be further related to the level of driving pressures applied during mechanical ventilation.

Some investigators had previously correlated the total duration of mechanical ventilation and the levels of plateau pressure with the long-term results of pulmonary function tests and high-resolution CT studies, suggesting a relationship between mechanical ventilation and pulmonary dysfunction $[6,23]$. This is the first time, however, that driving pressure was evaluated as a risk factor for long-term outcomes in survivors, and especially so after the general adoption of protective ventilation. In recent studies, driving pressures have been correlated with ARDS mortality, independently of tidal volume, PEEP and severity of illness, suggesting a causal role in the process of ventilator lung injury [24]. Commonly-as in this study-driving pressures and tidal volumes were weakly correlated, because lung compliance and ventilation strategies vary widely among patients [20]. Thus, we showed, similarly to the study of Amato et al. [20], that

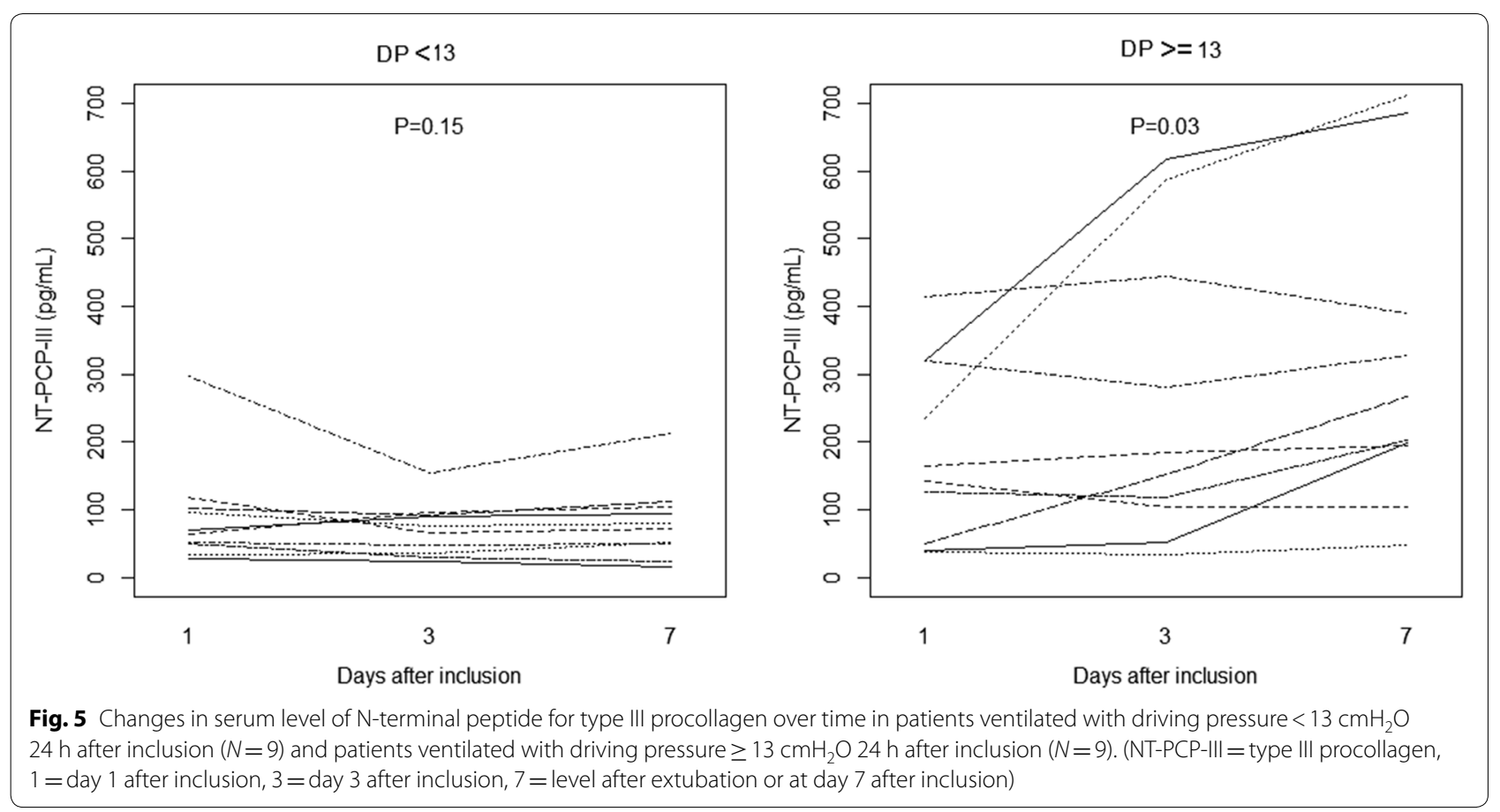


whereas a lower driving pressure was strongly correlated to better long-term outcomes, lower tidal volumes and higher baseline compliance (this latter reflecting lower severity of illness) were not.

A pro-fibrotic response to ARDS might be responsible for the physiologic abnormalities observed. Biomechanical interactions between cells and the extracellular matrix (ECM) proteins may be associated with the reorganization and remodeling of the ECM [25]. Collagen is the most important stress-bearing constituent of the parenchymal tissue and plays a critical role in mechanotransduction in lung repair and fibrosis development [26]. In the isolated rat lung or lung parenchymal strips, mechanical stretch resulted in enhanced NT-PCP-III gene expression, a by-product of type III collagen synthesis and a potential marker of collagen secretion [27, 28]. Interestingly, these studies suggested that the driving force (stress) applied to the tissue, but not the amplitude of resulting stretch, was responsible for collagen production.

Diffuse alveolar damage (DAD) is considered absent in approximately half of patients undergoing lung biopsy for nonresolving ARDS. The main alternatives to DAD were interstitial pneumonia and lung fibrosis, infections, cryptogenic organizing pneumonia and alveolar hemorrhage $[29,30]$. In our study, the increase in NT-PCP-III, associated with higher mean lung densities and lower lung volumes, was very suggestive of an intense fibrosis. Similarly to patients with idiopathic pulmonary fibrosis, the intense remodeling concomitantly reduced the total lung weight and volume, with a progressive increase in lung densities-but not necessarily an increase in lung tissue mass [31]. The reductions in FVC in our patients were not accompanied by an increased residual volume, a finding that might otherwise suggest some weakness associated with severity of illness [32]. Thus, we believe that most of the reduction in FVC observed in our patients was related to fibrosis and remodeling of lung tissue.

In the general population, a low $\mathrm{FVC}$ has been associated with increased respiratory symptoms, functional limitation and mortality [33-35]. Thus, the observed relationship between driving pressure and long-term QOL might be mediated by the low FVC, secondary to lung fibrosis. Of note, some of our patients presented FVC values of less than $70 \%$ of predicted values, and studies have shown that even smaller changes in FVC can strongly influence the QoL.

\section{Limitations}

The modest number of patients enrolled in a single center (representing $10 \%$ of the total number of patients included in the multicenter trial) may have compromised the power of this study to identify statistically significant relationships. The identified relationships, however, were consistent across different long-term variables, measured independently by $\mathrm{CT}$, function tests and questionnaire, suggesting the strength of the association. The independent blood samples also added consistency to our results.

Another limitation of our study was the unknown functional status of the enrolled patients, who were lost during follow-up. Additionally, though patients with an exacerbation of previous lung diseases were excluded before randomization, preexisting lung disease may have interfered in the results, as patients were not evaluated by pulmonary function tests prior to enrollment.

Finally, driving pressure was measured at $24 \mathrm{~h}$ of the beginning of the protocol. Ideally, we should consider some average exposition during the whole mechanical ventilation period. In this study, however, similarly to the previous study of Amato et al. [20], the values of driving pressure measured at day-one were strongly correlated to the levels measured during the next days. We may not exclude, however, that additional adjustments in mechanical ventilation after $24 \mathrm{~h}$ of the protocol could also be associated with late pulmonary function and structure.

\section{Conclusion}

In patients surviving after a moderate to severe ARDS there is an association between driving pressure measured $24 \mathrm{~h}$ after enrollment and lung function measured at 1 and 6 months after the ARDS onset, and this relationship was independent of tidal volume and independent of baseline compliance. These results suggest that, even in the context of protective tidal volume and plateau pressure, mechanical ventilation can still promote lung injury and fibrosis, highlighting the possible role of driving pressure in long-term outcomes.

\section{Abbreviations}

ARDS: acute respiratory distress syndrome; HRQoL: health-related quality of life; NT-PCP-III: N-terminal-peptide type III procollagen; 6MWT: 6-min walk test; QoL: quality of life; ICU: intensive care unit; COPD: chronic obstructive pulmonary disease; APACHE II: Acute Physiology and Chronic Health disease Classification System II; PEEP: positive end-expiratory pressure; $\mathrm{PaO}_{2}$ : arterial partial pressure of oxygen; $\mathrm{F}_{1} \mathrm{O}_{2}$ : inspired $\mathrm{O}_{2}$ fraction; ELISA: enzyme-linked immunosorbent assay; PFT: pulmonary function test; HRCT: high-resolution computed tomography; MPD: mean pulmonary density; TLV: total lung volume; TAV: total air volume; TLM: total lung mass; HU: Hounsfield unit; P15: threshold of 15\%; SF-36: 36-item Short-Form General Health Survey; SD: standard deviation; P/F: $\mathrm{PaO}_{2} / \mathrm{FIO}_{2} ; \mathrm{C}_{\text {stat }}$ : static compliance; PBW: predicted body weight; OLA: open lung approach; DAD: diffuse alveolar damage; HDP: high driving pressure; LDP: low driving pressure.

\section{Authors' contributions}

CTJ designed the work; acquired, analyzed, or interpreted the data for the work; and drafted the work. RRSS acquired and interpreted the data for the work and critically revised the work; ASH acquired and interpreted the data for the work and critically revised the work; ARSC analyzed and interpreted the 
data and critically revised the work; SG analyzed and interpreted the data and critically revised the work; MBPA designed the work, interpreted the data, and critically revised the work; CRRC designed the work, interpreted the data, and critically revised the work. All authors read and approved the final manuscript.

\section{Author details}

1 Divisão de Pneumologia, Cardiopulmonary Department, Heart Institute (InCor) University of São Paulo, INCOR Av. Dr. Enéas de Carvalho Aguiar, 44 Pinheiros, São Paulo, SP CEP 05403-900, Brazil. ${ }^{2}$ Laboratory of Pulmonary Engineering, Biomedical Engineering Program, Alberto Luiz Coimbra Institute of Post-Graduation and Research in Engineering, Federal University of Rio de Janeiro, Rio de Janeiro, Brazil. ${ }^{3}$ Laboratory of Respiration Physiology, Carlos Chagas Filho Institute of Biophysics, Federal University of Rio de Janeiro, Rio de Janeiro, Brazil. ${ }^{4}$ Respiratory Intensive Care Unit, University of São Paulo School of Medicine Hospital das Clínicas, São Paulo, Brazil.

\section{Acknowledgements}

Not applicable.

\section{Competing interests}

The authors declare that they have no competing interests.

\section{Availability of data and materials}

The datasets used and/or analyzed during the current study are available from the corresponding author on reasonable request.

\section{Consent for publication}

Not applicable.

\section{Ethics approval and consent to participate}

The Institutional Review Committee (CAPPesq) approved the study with the committee's reference number 1141/06.

\section{Funding}

Not applicable.

\section{Publisher's Note}

Springer Nature remains neutral with regard to jurisdictional claims in published maps and institutional affiliations.

Received: 8 July 2018 Accepted: 3 December 2018

Published online: 07 December 2018

\section{References}

1. Phua J, Badia JR, Adhikari NKJ, Friedrich JO, Fowler RA, Singh JM, et al. Has mortality from acute respiratory distress syndrome decreased over time?: A systematic review. Am J Respir Crit Care Med. 2009;179(3):220-7.

2. Azevedo LC, Park M, Salluh JI, Rea-Neto A, Souza-Dantas VC, Varaschin P, et al. Clinical outcomes of patients requiring ventilatory support in Brazilian intensive care units: a multicenter, prospective, cohort study. Crit Care. 2013;17(2):R63

3. Franca SA, Toufen C, Hovnanian ALD, Albuquerque ALP, Borges ER, Pizzo VRP, et al. The epidemiology of acute respiratory failure in hospitalized patients: a Brazilian prospective cohort study. J Crit Care. 2011;26(3):330. e1-8.

4. Herridge MS, Tansey CM, Matté A, Tomlinson G, Diaz-Granados N, Cooper A, et al. Functional disability 5 years after acute respiratory distress syndrome. N Engl J Med. 2011;364(14):1293-304.

5. Herridge MS, Cheung AM, Tansey CM, Matte-Martyn A, Diaz-Granados N, Al-Saidi F, et al. One-year outcomes in survivors of the acute respiratory distress syndrome. N Engl J Med. 2003;348(8):683-93.

6. Burnham EL, Hyzy RC, Paine R, Coley C, Kelly AM, Quint LE, et al. Chest $C T$ features are associated with poorer quality of life in acute lung injury survivors. Crit Care Med. 2013;41(2):445-56.

7. Kacmarek RM, Villar J, Sulemanji D, Montiel R, Ferrando C, Blanco J, et al. Open lung approach for the acute respiratory distress syndrome: a pilot, randomized controlled trial. Crit Care Med. 2016;44(1):32-42.
8. Espirometria Pereira C. Diretrizes para testes de função pulmonar. J Bras Pneumol. 2002;28(Supl 3):S1-82.

9. Pereira CAdeC, Sato T, Rodrigues SC. New reference values for forced spirometry in white adults in Brazil. J Bras Pneumol. 2007;33(4):397-406.

10. Neder JA, Andreoni S, Castelo-Filho A, Nery LE. Reference values for lung function tests. I. Static volumes. Braz J Med Biol Res. 1999;32(6):703-17.

11. Neder JA, Andreoni S, Peres C, Nery LE. Reference values for lung function tests. III. Carbon monoxide diffusing capacity (transfer factor). Braz I Med Biol Res. 1999;32(6):729-37.

12. Camilo GB, Carvalho ARS, Machado DC, Mogami R, Kasuki L, Gadelha MR, et al. Correlations between forced oscillation technique parameters and pulmonary densitovolumetry values in patients with acromegaly. Braz J Med Biol Res $=$ Rev Bras Pesqui médicas e biológicas/Soc Bras Biofísica. 2015;48(10):877-85

13. Carvalho AR, Spieth PM, Pelosi P, Beda A, Lopes AJ, Neykova B, et al. Pressure support ventilation and biphasic positive airway pressure improve oxygenation by redistribution of pulmonary blood flow. Anesth Analg. 2009:109(3):856-65.

14. Dirksen A, Friis M, Olesen KP, Skovgaard LT, Sørensen K. Progress of emphysema in severe alpha 1-antitrypsin deficiency as assessed by annual CT. Acta Radiol. 1997;38(5):826-32.

15. Dirksen A, Dijkman JH, Madsen F, Stoel B, Hutchison DC, Ulrik CS, et al. A randomized clinical trial of alpha(1)-antitrypsin augmentation therapy. Am J Respir Crit Care Med. 1999;160(5 Pt 1):1468-72.

16. Dowson LJ, Guest PJ, Stockley RA. Longitudinal changes in physiological, radiological, and health status measurements in alpha(1)-antitrypsin deficiency and factors associated with decline. Am J Respir Crit Care Med. 2001;164(10 Pt 1):1805-9.

17. Stolk J, Ng WH, Bakker ME, Reiber JHC, Rabe KF, Putter H, et al. Correlation between annual change in health status and computer tomography derived lung density in subjects with alpha1-antitrypsin deficiency. Thorax. 2003;58(12):1027-30.

18. ATS Committee on Proficiency Standards for Clinical Pulmonary Function Laboratories. ATS statement: guidelines for the six-minute walk test. Am J Respir Crit Care Med. 2002;166(1):111-7.

19. Ciconelli R, Ferraz M, Santos W, Meinão I. Brazilian-Portuguese version of the SF-36. A reliable and valid quality of life outcome measure. Rev Bras Reum. 1999;39(3):145-50.

20. Amato MBP, Meade MO, Slutsky AS, Brochard L, Costa ELV, Schoenfeld DA, et al. Driving pressure and survival in the acute respiratory distress syndrome. N Engl J Med. 2015;372(8):747-55.

21. Cheung AM, Tansey CM, Tomlinson G, Diaz-Granados N, Matté A, Barr A, et al. Two-year outcomes, health care use, and costs of survivors of acute respiratory distress syndrome. Am J Respir Crit Care Med. 2006;174(5):538-44.

22. Heyland DK, Groll D, Caeser M. Survivors of acute respiratory distress syndrome: relationship between pulmonary dysfunction and long-term health-related quality of life. Crit Care Med. 2005;33(7):1549-56.

23. Desai SR, Wells AU, Rubens MB, Evans TW, Hansell DM. Acute respiratory distress syndrome: CT abnormalities at long-term follow-up. Radiology. 1999;210(1):29-35.

24. Baedorf Kassis E, Loring SH, Talmor D. Mortality and pulmonary mechanics in relation to respiratory system and transpulmonary driving pressures in ARDS. Intensive Care Med. 2016;42(8):1206-13.

25. Cabrera-Benitez NE, Laffey JG, Parotto M, Spieth PM, Villar J, Zhang H, et al. Mechanical ventilation-associated lung fibrosis in acute respiratory distress syndrome: a significant contributor to poor outcome. Anesthesiology. 2014;121(1):189-98.

26. Suki B, Ito $S$, Stamenovic $D$, Lutchen KR, Ingenito EP. Biomechanics of the lung parenchyma: critical roles of collagen and mechanical forces. J Appl Physiol. 2005;98(5):1892-9.

27. Parker JC, Breen EC, West JB. High vascular and airway pressures increase interstitial protein mRNA expression in isolated rat lungs. J Appl Physiol. 1997:83(5):1697-705

28. Garcia CSNB, Rocco PRM, Facchinetti LD, Lassance RM, Caruso P, Deheinzelin $D$, et al. What increases type III procollagen mRNA levels in lung tissue: stress induced by changes in force or amplitude? Respir Physiol Neurobiol. 2004;144(1):59-70.

29. Cardinal-Fernández P, Bajwa EK, Dominguez-Calvo A, Menéndez JM, Papazian L, Thompson BT. The presence of diffuse alveolar damage on 
open lung biopsy is associated with mortality in patients with acute respiratory distress syndrome. Chest. 2016;149(5):1155-64.

30. Gerard L, Bidoul T, Castanares-Zapatero D, Wittebole X, Lacroix V, Froidure $A$, et al. Open lung biopsy in nonresolving acute respiratory distress syndrome commonly identifies corticosteroid-sensitive pathologies, associated with better outcome. Crit Care Med. 2018;46(6):907-14.

31. Coxson HO, Hogg JC, Mayo JR, Behzad H, Whittall KP, Schwartz DA, et al. Quantification of idiopathic pulmonary fibrosis using computed tomog raphy and histology. Am J Respir Crit Care Med. 1997;155(5):1649-56.

32. Hart N, Cramer D, Ward SP, Nickol AH, Moxham J, Polkey Ml, et al. Effect of pattern and severity of respiratory muscle weakness on carbon monoxide gas transfer and lung volumes. Eur Respir J. 2002;20(4):996-1002.

33. Mannino DM, Ford ES, Redd SC. Obstructive and restrictive lung disease and functional limitation: data from the Third National Health and Nutrition Examination. J Intern Med. 2003;254(6):540-7.

34. Guerra S, Sherrill DL, Venker C, Ceccato CM, Halonen M, Martinez FD. Morbidity and mortality associated with the restrictive spirometric pattern: a longitudinal study. Thorax. 2010;65(6):499-504.

35. Wan ES, Hokanson JE, Murphy JR, Regan EA, Make BJ, Lynch DA, et al. Clinical and radiographic predictors of GOLD-unclassified smokers in the COPDGene study. Am J Respir Crit Care Med. 2011;184(1):57-63.

\section{Submit your manuscript to a SpringerOpen ${ }^{\circ}$ journal and benefit from:}

- Convenient online submission

- Rigorous peer review

- Open access: articles freely available online

- High visibility within the field

- Retaining the copyright to your article

Submit your next manuscript at springeropen.com 